\title{
El signo en Vygotski y su vínculo con el desarrollo de los procesos psicológicos superiores ${ }^{1}$
}

\author{
The sign for Vygotsky and its connection with the \\ development of superior psychological processes
}

Rodolfo Vergel Causado²

\section{Resumen}

Presentamos algunos desarrollos en relación con la idea teórica de signo desde la perspectiva de Vygotski y esbozamos su íntima relación con el desarrollo de los procesos psicológicos superiores. En el ejercicio de caracterizar esta idea, nos vemos conminados a discutir el concepto de mediación semiótica. El vínculo con el desarrollo de los procesos psicológicos superiores nos obliga, por un lado, a precisar las ideas de internalización y desarrollo, y, por otro lado, las de intersubjetividad y dialogía. Nuestra argumentación sugiere que el desarrollo cognitivo parece depender del dominio progresivo de unos sistemas de mediación simbólica cada vez más complejos. En la parte final de este trabajo, y derivado de las ideas expuestas, nos atrevemos a señalar que en una línea cultural de desarrollo vygotskiana se requiere un complejo y relativamente largo proceso de apropiación cultural. Este proceso estaría orientado a propiciar grados crecientes de dominio autorregulado (consciente y voluntario) y descontextualizado de los instrumentos de mediación semiótica.

\section{Palabras clave}

Signo, mediación semiótica, procesos psicológicos superiores, internalización, desarrollo, intersubjetividad.

Abstract

We present some developments regarding the theoretical idea of the sign from Vygotsky's perspective and sketch its close relationship with the development of superior psychological processes. In doing this, we consider ourselves compelled to discuss the concept of semiotic mediation. The connection with the development of superior psychological processes obliges us, on the one hand, to define ideas of internalisation and development, and, on the other, to define ideas of intersubjectivity and dialogue. Our argumentation suggests that cognitive development seems to depend on the progressive domination of more and more complex systems of symbolic mediation. In the last section of this article, and as a result of the ideas presented, we dare, in particular, to point out that a Vygotskian cultural line of development requires a complex and relatively long process of cultural appropriation. This process seems to be orientated towards favouring growing levels of domination which is self-regulating (conscious and voluntary) and removed from its contexts of the instruments of semiotic mediation.

\section{Keywords}

Sign, semiotic mediation, superior psychological processes, internationalization, development, intersubjetivity

Artículo recibido el 26 de septiembre de 2013 y aprobado el 7 de febrero de 2014

1 La idea vygotskiana de signo ha sido fundamental como categoría analítica de la actividad semiótica de los estudiantes que participaron de la investigación doctoral “Formas de pensamiento algebraico temprano en alumnos de cuarto y quinto grados de Educación Básica Primaria (9-10 años)", bajo la dirección del Dr. Carlos Eduardo Vasco Uribe, desarrollada en el marco del Doctorado Interinstitucional en Educación, en la Universidad Distrital Francisco José de Caldas, Bogotá, Colombia. Los desarrollos aquí presentados hacen parte constitutiva del estado del arte de la tesis doctoral en mención.

2 Universidad Distrital Francisco José de Caldas, Bogotá, Colombia. El autor es estudiante del énfasis en educación matemática del Doctorado Interinstitucional en Educación de la Universidad Distrital Francisco José de Caldas. rvergelc@udistrital.edu.co. 
Universidad Pedagógica Nacional

Facultad de Humanidades

La idea de signo en los planteamientos de Vygotski es fundamental dentro de su propuesta psicológica y sería necesario profundizar en ella si deseamos aproximarnos, en parte, al sentido del desarrollo de su obra. Un principio básico en sus ideas al respecto sugiere que el signo mediatiza la relación del ser humano con otro y la relación del ser humano consigo mismo. Cárdenas (en prensa) señala que desde la comunicación, la mediación instaura las intenciones, puntos de vista, perspectivas, modalidades y estrategias con que nos comunicamos. Por ello, la mediación lingüística es una condición sine qua non de la manera como el sujeto se sitúa en el mundo y se relaciona con los demás, a través de actos de conciencia, conocimiento, conducta y comunicación.

Podríamos afirmar que el concepto de interés emerge de estos cuatro actos. Este regula el entendimiento, modula la razón teórica y la razón práctica y configura el campo de la experiencia; de ahí sus vínculos estrechos con la mediación. Según Cárdenas (en prensa), la mediación, desde la conciencia, le da piso al sentido, marca la disposición del lenguaje hacia un cierto objeto desde un sujeto que hace y decide de manera deliberada y responsable. Por tanto, el signo cumple el papel de una operación significativa. Aún más, los signos no se limitan únicamente a su función representativa, ${ }^{3}$ la elección de ellos no es neutra o independiente y dicha elección orienta el destino en el cual se expresa el pensamiento, el destino de la comunicación.

Esta relación epistemológica es vista, entonces, de tal forma que el objeto de conocimiento es inseparable de la actividad de los individuos. Según Cole (1999), Marx sostenía que el objeto o producto producido no es externo e indiferente a la naturaleza del productor: es su actividad cosificada o petrificada. El exterior, histórica y culturalmente constituido, provee el material de base con el cual se van formando los individuos y los conocimientos que estos adquieren a través de procesos sociales de interiorización. Entendemos interiorización, en el sentido de Vygotski, inicialmente, como un

3 El énfasis es mío. proceso de formación de la mente a través de la interacción social, proceso en el cual se conserva el carácter social de las funciones externas al hacerse internas; de esta manera es posible aseverar que las funciones psicológicas superiores son internalizadas desde lo social.

La producción de significados por parte de un sujeto dentro de una cultura en particular, encuentra asidero en la idea de sujetos semióticos en el sentido de Lamiell (2003, citado por Valsiner, 2012), quien enfatiza así el hecho de que, bajo todas las circunstancias de la vida, los seres humanos son constructores activos de significado. Al respecto, Sánchez (2001, p. 31) precisa:

El ser humano como sujeto semiótico, como sujeto capaz de producir e interpretar y negociar significados se forma como tal en la medida que se apropia activamente de los instrumentos semióticos producidos, dentro de la historia cultural de la humanidad. De forma tal que el desarrollo psicológico es indisociable de la vida en sociedad y de las interacciones del individuo con los otros de su grupo familiar y social. El sujeto enunciador, intérprete y negociador, el sujeto deliberante, dialógico se construye como tal en tanto se integra en las distintas redes de significado que constituyen el tejido social. El sujeto humano como sujeto cultural es alguien sujetado, normatizado por los contenidos de su cultura y es en el marco de esta sujetación que es posible hablar de autorregulación.

Para comprender el significado de los signos, no los podemos reducir simplemente a lo que ellos representan. Debemos comprender el tipo de actividad que ellos permiten realizar. Podemos afirmar, entonces, que los problemas de los estudiantes no están solamente en las estructuras semióticas complicadas que ellos deben manejar sino principalmente en el sistema de prácticas asociadas con estas representaciones semióticas. En armonía con el anterior señalamiento, D'Amore (2001) afirma que no basta construir un sistema de reglas para los signos y hacerlo explícito, posibilitando operar correctamente marcas en un papel, sino que se debe asignar sentido a la operatividad del signo. 
Con el interés de profundizar los aspectos anteriores, abordamos en la primera sección de este artículo la idea de signo, fundamentalmente desde la perspectiva vygotskiana, el concepto de mediación semiótica y las ideas de internalización y desarrollo. Los elementos íntimamente ligados de intersubjetividad y dialogía son presentados en la segunda sección. En la tercera parte del presente escrito nos proponemos abordar el desarrollo de los procesos psicológicos superiores y su relación con los signos. En la última sección hacemos una síntesis de lo expuesto y presentamos algunas observaciones finales.

\section{El signo en Vygotski, la mediación semiótica y las ideas de internalización y desarrollo}

De acuerdo con la perspectiva de Vygotski, los signos se interponen entre cualquier función natural psicológica del ser humano y su objeto, cambiando de raíz las propiedades de dicha función. Según Vygotski (1931/2000, p. 123), "en la estructura superior el signo y el modo de su empleo es el determinante funcional o el foco de todo el proceso". Lo mismo que la utilización de una u otra herramienta determina todo el mecanismo de la operación laboral, así también el carácter del signo utilizado constituye el factor fundamental del que depende la construcción de todo el proceso.

Pero, por otro lado, Vygotski (1931/2000, p. 146) sostiene que "el signo, al principio, es siempre un medio de relación social, un medio de influencia sobre los demás y tan sólo después se transforma en medio de influencia sobre sí mismo". Vygotski afirma que más allá de influenciar la conducta de los demás, el signo adquiere la peculiaridad de ser un instrumento que transforma al sujeto mismo. Luego, podríamos hablar de la condición procesual del significado de un signo (Vygotski, 1987), en el sentido de que el significado no se descubre, sino que él mismo se materializa, gesta y transforma durante una situación comunicativa singular gracias al intercambio lingüístico establecido por los usuarios entre sí.
En otras palabras, el término signo es utilizado por Vygotski con el sentido de poseedor de significado (Wertsch, 1985/1988, p. 34). De aquí que la base estructural de las formas culturales del comportamiento es la actividad mediadora (Vygotski, 1931/2000), la utilización de signos externos como medio para el desarrollo ulterior de la conducta.

En esta misma dirección, Castorina \& Carretero (2012, p. 30), al describir el papel que desempeñan los signos en la cognición, señalan que "la incorporación de signos en el pensamiento transforma el grado de elaboración cognitiva”. En una discusión que intenta aclarar lo semiótico, estos dos autores plantean que a pesar de sus divergencias respecto del papel que tienen los signos en el pensamiento, tanto Piaget con su función semiótica como Vygotski con su mediación semiótica incorporan una variedad de signos, sin distinguir sus particularidades ni su complejidad cognitiva.

Una distinción importante que establecen estos dos autores es "el grado en que los signos están integrados en un sistema" (Castorina \& Carretero, 2012, p. 30). Esto significa, indudablemente, una afectación en la cognición, pues estos signos pertenecen a un sistema que tiene reglas y conlleva un sistema de significación. Más precisamente, Castorina \& Carretero (2012, pp. 30-31) afirman:

La creación y utilización de un signo particular por parte de una persona, por importante que sea, no es comparable con el uso de signos que pertenecen a un sistema y cuyos significados están determinados por un conjunto de reglas. La complejidad de significados y el valor instrumental de unos y otros no es comparable. Los signos que forman parte de un sistema establecen un entramado semántico complejo y su uso repercute de forma profunda en la cognición.

Esta afectación en la cognición coincide con los planteamientos ya expuestos por Vygotski (1929), para quien toda la estructura de los procesos que despliega un sujeto estará determinada por el carácter de los medios (por ejemplo, signos, artefactos) que ha seleccionado para llevar a cabo dichos procesos. Sin embargo, esta complejidad cognitiva no 
Universidad Pedagógica Nacional

Facultad de Humanidades

obedece solamente a los sistemas de signos en sí mismos. Nos parece fundamental señalar que si bien el signo refleja, porque la representación es su característica, ella no es simple ni directa.

En la concepción arquitectónica del signo, Bajtín (1929/1992) afirma que este adopta maneras de representar, adopta acentos típicos de la manera de participación social de los usuarios, para lo cual entra en el universo de lo axiológico, de la valoración, de lo ideológico. En este sentido, la conciencia solo deviene conciencia al llenarse de un contenido ideológico, es decir, sígnico y, por ende, solo en el proceso de interacción social (Bajtín, 1929/1992). El enunciado, afirma Bajtín, dice del sujeto; esta psicología del cuerpo social bajtiniana hace visible el horizonte social y cultural en donde vive. En esta dirección se inscriben los orígenes sociales de los procesos psicológicos superiores que Vygotski los matiza en términos del funcionamiento interpsicológico, tal y como se refleja en su formulación de la ley genética del desarrollo cultural:

\section{Cualquier función, presente en el desarrollo cultural del niño, aparece dos veces o en dos planos distintos. En primer lugar aparece en el plano social, para hacerlo, luego, en el plano psicológico. En principio, aparece entre las personas y como una categoría interpsicológica, para luego aparecer en el niño como una categoría intrapsicológica. Esto es igual- mente cierto con respecto a la atención voluntaria, la memoria lógica, la formación de conceptos y el desarrollo de la volición. Podemos considerar esta argumentación como una ley en el sentido estricto del término, aunque debe decirse que la internaliza- ción transforma el proceso en sí mismo, cambiando su estructura y funciones. Las relaciones sociales o relaciones entre las personas subyacen genéticamen- te a todas las funciones superiores y a sus relaciones. (Wertsch, 1985/1988, pp.77-78)}

De esta formulación podemos destacar, al menos, dos ideas o elementos importantes. Primero, la idea de internalización, la cual insta a pensar que no es posible establecer la relación entre los dos planos en términos de reflejo, esto es, no parece colegirse un "modelo transferencial de internalización" (Wertsch, 1985/1988, p. 80), muy al contrario, para Vygotski los procesos psicológicos superiores internalizados (pensamiento lógico, la deducción, la abstracción, la categorización, la generalización, entre otros) no son meras copias de procesos externos interpsicológicos, pues como bien lo anota el mismo autor, la internalización transforma el proceso en sí cambiando su estructura y funciones. Los instrumentos con que mediatizamos la actividad humana, aparte de cumplir su función pragmática de permitirnos llevar a cabo la actividad misma, son fundamentalmente importantes en tanto que afectan y alteran nuestras funciones psíquicas superiores.

Según Sánchez (2001, p. 34):

Para Vygotski el concepto de internalización (interiorizatziya) es esencial en la explicación del desarrollo de las funciones mentales superiores. Según Gal'perin "lo que no es mental se transforma en mental, según su propia afirmación (de Vygotski) las funciones mentales superiores se desarrollan originalmente bajo la forma de actividad externa y solamente se convierten en procesos mentales del individuo como un resultado de la internalización".

Según Kozulin (2000), Vygotski trazó una primera distinción entre los procesos mentales naturales "inferiores" de la percepción, la atención, la memoria y la voluntad, y las funciones psicológicas culturales "superiores" que aparecen bajo la influencia de los instrumentos simbólicos. Las funciones inferiores no desaparecen, sino que son sustituidas e incorporadas a las culturales. De ahí la importancia de los problemas que proponemos a los estudiantes, por cuanto como afirma Vygotski (1929), si la tarea o el problema no están por encima de las capacidades naturales del niño, él puede dominarlos por el método natural o primitivo.

La segunda idea a destacar es la de desarrollo, que, lejos de ser ingenua en los planteamientos de Vygotski, cobra especial relevancia en su teoría del desarrollo genético. De acuerdo con Wertsch (1985/1988), Vygotski define el desarrollo en términos de aparición y transformación de las diversas formas de mediación y su noción de interacción y su relación con los procesos psicológicos superiores 
implica necesariamente los mecanismos semióticos. Es claro que para Vygotski el desarrollo es considerado en términos de saltos revolucionarios fundamentales más que en términos de incrementos cuantitativos constantes.

Es más, él defendió los puntos principales del desarrollo en términos de los cambios experimentados en la forma de mediación utilizada, esto es, en las acciones del sujeto a través del uso de instrumentos de mediación semiótica y su toma respectiva de conciencia de este uso. En este sentido, afirma Noel (1933/1995, p. 81):

[...] la mediación en general toma un nuevo significado. La esencia deja de confundirse con el movimiento mismo de la reflexión; es, de cierta manera, el elemento donde se produce el movimiento y lo hace posible. Las determinaciones de la reflexión dejan de flotar, por así decirlo, en el vacío y encuentra un soporte en la esencia.

El desarrollo de la conciencia de un niño (Leontiev, 1983, citado en Kozulin, 2000, p. 40) "se produce como resultado del desarrollo del sistema de operaciones psicológicas que, a su vez, está determinado por las relaciones genuinas entre el niño y la realidad". Al respecto, Kozulin (2000, p. 79) destaca este tipo de relaciones y la considera íntimamente ligada a la noción de trabajo:

Hegel vincula la aparición de la conciencia y la autoconciencia del ser humano con el proceso de actividad mediada que es el trabajo. La noción filosófica de mediación ya sugiere toda una gama de posibles agentes mediadores. En primer lugar, el trabajo presupone unos instrumentos materiales interpuestos entre el individuo y el objeto natural. Aunque estos instrumentos están dirigidos a objetos naturales, también tienen una influencia recíproca en el individuo, modificando así su tipo de actividad y de cognición. En segundo lugar, como el trabajo siempre es un trabajo para alguien más, las características sociales y psicológicas de esa otra persona también entran en la ecuación. Por último, puesto que el trabajo es imposible sin representaciones simbólicas, estos símbolos y sus medios de transmisión pasan a ser dos agentes mediadores más.
Para Kozulin, la conciencia del sujeto está estrechamente vinculada con la interacción, no sólo con el objeto natural sino también con el otro. Esta relación compleja que construye la individualidad del sujeto a partir del otro, como en una relación de alteridad bajtiniana, influye de manera esencial en el desarrollo de la conciencia; al decir Bajtín (1979/2009, p. 360) "la conciencia del hombre despierta envuelta en la conciencia ajena", lo cual sugiere que la conciencia adquiere su identidad dentro de la práctica social reflexiva. Coincidimos con Radford (2013, p. 27) cuando señala:

La conciencia individual es una forma específicamente humana de reflexión subjetiva sobre la realidad concreta en el curso de la cual tomamos sensibilidad de las formas culturales que nos permite considerar, reflexionar, comprender, disentir, objetar y sentir acerca de otros, de nosotros mismos y de nuestro mundo.

El llamado que hacen Kozulin y Radford en el sentido de buscar los orígenes de la actividad consciente en lo externo, en el otro, en lo social, ha sido discutido también por Luria, tal y como lo reporta Wertsch (1998, p. 26):

Para explicar las formas altamente complejas de la conciencia hay que ir más allá del organismo humano. No hay que buscar los orígenes de la actividad consciente y la conducta "categórica" en las depresiones del cerebro humano o en las profundidades del espíritu, sino en las condiciones externas de vida. Por sobre todo, esto significa que hay que buscar esos orígenes en los procesos externos de la vida social, en las formas sociales e históricas de la existencia humana.

Coincidimos con Wertsch (1985/1988) en señalar que los tres temas que constituyen el núcleo de la estructura teórica de Vygotski son:

1. la creencia en el método genético o evolutivo

2. los procesos psicológicos superiores tienen su origen en procesos sociales, y

3. los procesos mentales o cognitivos pueden entenderse solamente mediante la comprensión de los instrumentos y signos que actúan como mediadores. 
Universidad Pedagógica Nacional

Facultad de Humanidades

La creencia en el método genético, de acuerdo con Vygotski, significa que el pensamiento se puede desarrollar. Vygotski se centró en estudiar cómo el funcionamiento interpsicológico podía ser estructurado de tal manera que maximizara el crecimiento del funcionamiento intrapsicológico. "La instrucción solamente es positiva cuando va más allá del desarrollo. Entonces despierta y pone en funcionamiento toda una serie de funciones que, situadas en la zona de desarrollo próximo, se encuentran en proceso de maduración" (Wertsch, 1985/1988, p. 87).

En su trabajo sobre El problema del desarrollo cultural del niño, Vygotski (1929) deja entrever que cuando deliberadamente interferimos en el curso de los procesos de comportamiento, podemos hacerlo sólo en conformidad con las mismas leyes que rigen estos procesos en su curso natural. La inclusión en cualquier proceso de un signo, plantea Vygotski (1929), remodela toda la estructura de las operaciones psicológicas, así como la inclusión de una herramienta remodela toda la estructura de una operación de trabajo.

Las fronteras entre el funcionamiento social y el individual son bastante permeables en su descripción y su énfasis está puesto en las transformaciones entre los procesos intermentales (interpsicológicos) e intramentales (psicológicos) más que en la brecha que los separa. La composición de las funciones psíquicas superiores (Wertsch, 1998), su estructura genética y sus medios de acción, esto es, sus formas de mediación, en una palabra, toda su naturaleza, es social. Aun cuando nos afinquemos en los procesos psíquicos (internos), debemos reconocer que su naturaleza permanece cuasi social. En su propia esfera privada, los seres humanos retienen las funciones de la interacción social.

Desde la perspectiva de Vygotski, el funcionamiento intramental es social no solo por estar situado socioculturalmente, sino también porque como bien lo anota Wertsch (1998), retiene las funciones de la interacción social. Por ejemplo, muchas formas de resolución de problemas en el nivel individual son consideradas inherentemente dialógicas debido al hecho de que derivan de la participación en encuentros dialógicos en el plano intermental (Wertsch, 1985/1988). Esta declaración se entiende siempre y cuando se acepte que para Vygotski las formas de discurso dialógico que median en los procesos intermentales son usadas para conformar el plano intramental.

Según Kozulin (2000), para Vygotski el desarrollo psicológico es un proceso lleno de trastornos, crisis y cambios estructurales. Este proceso (de desarrollo psicológico) se puede apreciar tanto desde una perspectiva microgenética como macrogenética. En términos de Kozulin (2000), estas dos perspectivas están caracterizadas de la siguiente manera:

Microgenéticamente el proceso de desarrollo se manifiesta en la reestructuración del pensamiento y de la conducta del niño bajo la influencia de un nuevo instrumento psicológico. Macrogenéticamente, el desarrollo se manifiesta como un proceso que dura toda la vida, dedicado a la formación de un sistema de funciones psicológicas correspondientes a todo el sistema de medios simbólicos disponibles en una cultura dada. (Kozulin, 2000, p. 31)

Kozulin, en este mismo apartado, afirma que "la educación es un elemento integral de este proceso macrogenético". En vez de una superestructura construida sobre los fundamentos de las funciones psicológicas, señala este autor, la actividad educativa se contempla como un proceso que modifica de una manera radical esos mismos fundamentos (Vygotsky, 1978, citado por Kozulin, 2000). Cole (1999, citado por Kozulin, 2000) llegó a una conclusión similar: las consecuencias cognitivas de la educación formal y del empleo de los instrumentos psicológicos asociados con ella no tienen un carácter absoluto, sino que dependen en gran medida de la estructura de las actividades predominantes en una cultura o una subcultura dada.

\section{Las ideas de intersubjetividad y dialogía}

La intersubjetividad se relaciona con la medida en que los interlocutores de una situación comunicativa comparten una perspectiva. Desde un punto de vista fenomenológico, Bajtín (1929/1992) examina 
esta idea desde la concreta relación yo-otro. De entrada, el énfasis en el sujeto como un ente social pone en cuestión el concepto mismo de identidad, al introducir la categoría de la alteridad como parte constituyente del yo, como su antecedente obligado y referente necesario. Al sujeto se le concibe más allá del eje egocéntrico, para ubicarlo en la red de relaciones dialógicas que establece consigo mismo y con la alteridad (en realidad, con una multiplicidad de otros).

El yo no puede comprenderse íntegramente sin la presencia del otro, sin la actuación del otro, sin el discurso del otro. La identidad pierde así su eje egocéntrico y monológico; se vuelve heteroglósica. Identidad y alteridad se entienden, entonces, como conceptos interdependientes, complementarios, de una naturaleza relacional y relativa. En esta dirección, Cárdenas \& Ardila (2009, p. 44) dicen:

La noción de sujeto que se desprende de Bajtín no equivale a individuo ni obedece al concepto de esencia o a algo que preexiste a lo social. El sujeto es un continuo hacerse, sin una esencia específica $\mathrm{y}$ sin identidad fija que va surgiendo en la medida en que se construye socialmente el discurso, en la medida en que va asumiendo posiciones en el universo ideológico de lo social. El sujeto es el conjunto de posiciones que puede ocupar el ser humano en el transcurso de su vida.

Esta idea de sujeto en tanto acontecimiento del ser, como un continuo hacerse, paga tributo necesariamente a la presencia del otro en una relación intersubjetiva. A este respecto, Cárdenas (2009, p. 13) puntualiza:

El sujeto se da en la intersección con el otro, es una zona fronteriza que no está perfectamente delimitada, ni constituida ni fijada en el tiempo y en el espacio. Es una construcción que avanza en la medida en que la mirada se orienta en dirección de la conciencia del otro, en función de la ideología.

Es necesario precisar que es gracias al lenguaje simbólico que el sujeto se realiza como constructor de mundos y en los cuales se instaura con otros, no en abstracto (Cárdenas, 2009) sino en contextos pragmáticos de interacción. El sujeto se define, entonces, por el acontecimiento del ser (Cárdenas, 2009, p. 14) "y el ser acontece siempre en relación con el otro, en cuanto actúa frente al otro, al lado del otro, junto con el otro, en el mundo de la vida y en la cultura".

Wertsch (1998), inspirado en el trabajo de Ragnar Rommetveit, al referirse a la categoría de intersubjetividad, plantea:

El problema básico de la intersubjetividad humana se vuelve [...] una cuestión que tiene que ver con qué sentido y bajo qué condiciones dos personas que se involucran en un diálogo pueden trascender sus mundos privados diferentes. Y la base lingüística para esta empresa no es, según sostengo, un repertorio fijo de significados "literales" compartidos, sino bosquejos muy generales y parcialmente negociados de contratos concernientes a la clasificación y atribución inherente al lenguaje ordinario. (Rommetveit, 1979, citado por Wertsch, 1998, p. 177)

La idea de intersubjetividad, a nuestro juicio, se encuentra íntimamente relacionada con la idea bajtiniana de dialogía (Bajtín, 1929/1992), según la cual el acto discursivo obedece a un carácter responsivo y no solo significativo. Las ideas de Bajtín sugieren que el enunciado encarna otros enunciadores. $\mathrm{He}$ ahí el vínculo con la historicidad propuesta por Vygotski en las prácticas sociales y en el lenguaje. Por lo que en Bajtín, la relación entre sujetos tiene como marco global al dialogismo, que de paso sea dicho, se constituye en el principio filosófico central de su concepción del lenguaje y de la vida social en su conjunto.

En la obra del filósofo, los significados del dialogismo son diversos, pero un punto de partida para su comprensión es su etimología, que refiere a la interacción de dos o más logos, cada uno con sus propios marcos axiológicos, voliciones y posicionamientos. El enunciado, el discurso, y en general su concepción global de la comunicación humana, derivan todos del principio dialógico, de la fundante relación yootro. Tal y como sugiere García (2006, p. 50):

[...] recordemos que una teoría bajtiniana del discurso afirma que no sólo se trata de lo que 
Universidad Pedagógica Nacional

Facultad de Humanidades

acontece "al interior" de nuestra propia conciencia, sino en la frontera de la conciencia de otro sujeto cabal, completo, precisamente en el umbral. Para Bajtín, el más alto grado de socialidad estriba en el hecho de que cada experiencia interna, cada sujeto, termina por toparse con otro. Toda la "ontología del yo" en el sentido bajtiniano se dialogiza, en primera instancia, en esta frontera, y no puede realizarse más que en este lugar de encuentro lleno de tensiones. El sujeto siempre es el producto de su interacción con otros sujetos.

En esta perspectiva, la comunicación humana como acontece en la vida real no es un mero intercambio de mensajes basado en un código compartido y en un consenso de sentido, sino que, por el contrario, se trata siempre de una tensión vital entre logos fundamentalmente distintos, cada uno con su propia posición axiológica respecto al mensaje, a su objeto, al código, al emisor, así como a los contextos de interacción.

El sentido de un enunciado, nos enseña Bajtín, incluye la respuesta del receptor y no se realiza tomando las palabras mecánicamente, como si fuesen entradas de diccionario, colocadas una tras otra de acuerdo con reglas sintácticas, sino como elementos cargados de valoraciones sociales, puestas en juego en el proceso de la comunicación interdiscursiva.

Bajtín (1929/1992) señala cómo desde la temprana adquisición del lenguaje y a lo largo de la vida, el hombre se inicia como un ser social y se desarrolla como tal construyendo su individualidad a partir del otro, de las acciones y del discurso del otro, para continuar con este una íntima y compleja relación. El sujeto social se forma discursivamente, en el proceso comunicativo de yo con el otro, es decir que el discurso propio se construye en relación con el discurso ajeno, en el proceso de una íntima y constante interacción. Las respectivas identidades se construyen en el proceso de la comunicación interdiscursiva. Así pues, en Bajtín el ser presenta un carácter intrínsecamente dialógico, "ser es ser para otro y a través del otro para mí".

Por supuesto, el lenguaje pasa a ser entendido, entonces, como un aspecto nuclear de la consti- tución subjetiva de la persona, en la medida que establece un nudo entre el orden de lo psicológico y el orden de la cultura, a través de los significados. El lenguaje no es ni un mero "compañero" de las acciones, tampoco un simple medio de expresión de ideas, es un instrumento para transformar la realidad (Kozulin, 2000) y hacer que, a cuentas de ser algo dado, sea algo que se está desarrollando. El lenguaje es un constante flujo de sentido cargado axiológicamente (Bajtín, 1929/1992).

$\mathrm{Al}$ decir de Cárdenas (en prensa), cuando abstraemos, generalizamos, identificamos, mencionamos, evocamos, indexamos la realidad y sus eventos, creamos analogías, adoptamos una actitud o punto de vista ante las cosas. En este sentido, anota este autor, la mediación teje una red que se intensifica y se extiende en complejidad, al punto que es imposible hablar de un reflejo isomórfico de la realidad en la mente humana. Para Cárdenas resulta clave reconocer que la realidad es una construcción lastrada por la experiencia del hombre, llena de vivencias, de focos de atención específicos, preñada de puntos de vista, abordable desde numerosas perspectivas que enmarcan diversas aproximaciones a ella. Estos elementos claramente desvirtúan la idea de mera representación que algunos autores le han querido conferir al lenguaje.

El papel del lenguaje nos parece fundamental, lejos de esa idea representacionista. Más aún, para la comprensión del papel de la educación en el desarrollo del sujeto social, considerar el lenguaje es clave, dada la estrecha relación que tiene con el desarrollo del pensamiento y del conocimiento (Vygotski, 1934/2007). Desde esta perspectiva, tomando el lenguaje como potencial semiótico y noético (Duval, 1995/1999), es posible reconocer, en él, tres dimensiones (Calderón, 2005):

- La ética, que vincula sujeto discursivo y aspectos de tipo normativo, axiológico y actitudinal de la comunicación y de la significación compartidas socialmente.

- La psicológica, considerando el lenguaje como acción humana, que pone en juego aspectos de tipo cognitivo y de tipo semiótico e infor- 
mativo; es decir, el desarrollo de procesos de significación que exigen el permanente proceso de semiotización.

- La social, que destaca las funciones comunicativa e interactiva del lenguaje.

Estas tres dimensiones, que solo separamos para propósitos analíticos, están presentes en toda producción y desarrollo discursivo; de ahí la importancia de considerarlas en aras de la comprensión de los distintos aspectos manifiestos en la discursividad de los hablantes. Discursividad que por supuesto no es ajena a los instrumentos de mediación semiótica que el sujeto pone en acción. De esto advierte Wertsch (1991, p. 46):

Contrastando con muchos análisis contemporáneos del lenguaje, con su acento puesto en la estructura de los sistemas de signos, con independencia de cualquier función mediadora que puedan cumplir, Vygotski encaró al lenguaje y otros sistemas de signos como parte y como mediadores de la acción humana.

Podemos inferir que la principal característica distintiva del aprendizaje y el desarrollo psicológico del ser humano, según Vygotski, reside en la intervención de instrumentos psicológicos simbólicos en este proceso. Para decirlo una vez más, los signos, los textos escritos, los sistemas numéricos, las fórmulas, los gráficos y otros recursos simbólicos, modifican radicalmente el proceso de aprendizaje, permitiendo a los estudiantes organizar y regular sus propios procesos cognitivos con la ayuda de estos instrumentos culturales. En este sentido, los canales por donde transita la interacción entre individuos, ya se encuentra moldeada por formas culturales de discurso que son a la vez productores y reguladores del saber, en otras palabras, las maneras de conocer y lo que conocemos hoy en día lleva consigo las trazas y los sedimentos de formas históricas y culturales, formas que "contaminan" los procesos psicológicos.

\section{Sobre el desarrollo de los procesos psicológicos superiores y su relación con los signos}

Pero, ¿ ¿cuál es el origen de estos procesos psicológicos?, ¿desde dónde fundamenta Vygotski esta idea? Nos parece importante subrayar que Vygotski asume una perspectiva marxista en la elaboración de su idea de procesos psicológicos. Sostiene, de acuerdo con Marx, que los cambios históricos que se producen en la sociedad y en la vida material conllevan, al mismo tiempo, otros cambios en la "naturaleza humana" (en la conciencia y conducta). Vygotski fue el primero en relacionar estas ideas con las cuestiones psicológicas específicas (Wertsch, 1991). De Engels, por ejemplo, basado en el concepto de trabajo humano y uso de herramientas, elaboró la idea de que a través de estos el hombre cambia la naturaleza y, simultáneamente se transforma a sí mismo.

Vygotski explota de esta manera el concepto de herramienta de un modo particular basado en las ideas de Engels: la especialización de la mano significa la herramienta y ésta presupone la actividad específicamente humana, la reacción transformadora del hombre sobre la naturaleza. El animal utiliza la naturaleza exterior e introduce cambios en ella pura y simplemente con su presencia, mientras que el hombre, mediante sus cambios, la hace servir a sus fines, la domina. A juicio de Vygotski (1929), podemos transformar la naturaleza hacia el exterior y ponerla al servicio de nuestros fines únicamente de conformidad con las leyes mismas de la naturaleza.

Podemos, entonces, llegar a pensar que Vygotski concibió los procesos psicológicos superiores como una aplicación psicológicamente importante del materialismo histórico y dialéctico. ${ }^{4}$ Un eje central de este método consistía en que todos los fenómenos debían ser estudiados como procesos en constante

4 En Hegel (1817/2004), el término dialéctica tiene una larga historia. De él se destacan cuatro acepciones fundamentales: (1) la dialéctica como método de la división lógica, conforme a la cual se clasifica un concepto genérico en sus especies; (2) la dialéctica como lógica de lo probable; (3) la dialéctica como término para designar a la lógica entera y (4) la dialéctica como método encaminado a superar las oposiciones de dos términos (tesis-antítesis) en uno nuevo: la síntesis (p. xxxix). 
Universidad Pedagógica Nacional

Facultad de Humanidades

movimiento y cambio. Vygotski destacó que los procesos psicológicos superiores surgen de la actividad humana mediada por instrumentos psicológicos de carácter semiótico. Por lo tanto, el desarrollo cognitivo parece depender del dominio progresivo de unos sistemas de mediación simbólica cada vez más complejos.

Vygotski (1931/2000, p. 34) sugiere:

La cultura origina formas especiales de conducta, modifica la actividad de las funciones psíquicas, edifica nuevos niveles en el sistema de comportamiento humano del desarrollo. En el proceso de desarrollo histórico, el hombre social modifica los modos y procedimientos de su conducta, transforma sus inclinaciones naturales y funciones, elabora y crea nuevas formas de comportamiento específicamente culturales.

El lenguaje, la escritura y las distintas formas literarias son los instrumentos culturales que proporcionan el mecanismo formal para el dominio de los procesos psicológicos.

Wertsch (1985/1988) plantea que para Vygotski un primer criterio que caracteriza las funciones psicológicas superiores (pero no las elementales) es su origen y naturaleza social. De esta forma, sugería Vygotski, no es la naturaleza, sino la sociedad la que, por encima de todo, debe ser considerada como el factor determinante del comportamiento humano. En esta dirección, Vygotski (1931/2000, p. 151) puntualiza:

Todas las funciones psíquicas superiores son relaciones interiorizadas de orden social, son el fundamento de la estructura social de la personalidad. Su composición, estructura genética y modo de acción, en una palabra, toda su naturaleza es social; incluso al convertirse en procesos psíquicos sigue siendo cuasi-social. El hombre, incluso a solas consigo mismo, conserva funciones de comunicación.

Un segundo criterio para diferenciar las funciones psicológicas superiores de las elementales es el de la mediación. En este sentido, sostiene Wertsch (1985/1988), la concepción vygotskiana del control voluntario, la realización consciente y la naturaleza social de los procesos psicológicos superiores presuponen la existencia de herramientas psicológicas o signos, que pueden ser utilizados para controlar la actividad propia y la de los demás. ${ }^{5}$

\section{Síntesis y observaciones finales}

Las nociones de signo y de mediación semiótica son analíticamente importantes. La presencia de estímulos creados junto con estímulos dados es la característica diferencial de la psicología humana. Estamos de acuerdo con Cole \& Wertsch (1996) cuando sostienen que los instrumentos o herramientas psicológicas recrean y reorganizan la estructura del comportamiento humano. Un corolario de la argumentación desarrollada en este trabajo podríamos enunciarlo de la siguiente manera: los instrumentos o recursos con los cuales se realiza la actividad matemática condicionan las formas como los estudiantes se apropian, construyen o resinifican dicha actividad y desde luego las maneras de pensar. Corolario que indudablemente pone de manifiesto una idea de conciencia ligada al desarrollo del sistema de operaciones psicológicas.

Estamos de acuerdo con Sánchez (s.f., p. 80) cuando señala que:

La perspectiva triádica de Vygotski [sujeto-signoobjeto] aporta elementos que resultan claves para entender el pasaje de lo interindividual y lo colectivo a lo individual, dándole un lugar central a la interacción y permitiendo un avance importante en la conceptualización de la interacción social. Es posible decir que el aporte específico de los planteamientos vygotskianos en este sentido, consiste en caracterizar la interacción como una relación mediada semióticamente.

De esta manera, afirma la autora, el papel mediador del signo viene a ser un rasgo específico de toda relación humana, el cual convoca, al mismo tiempo,

5 Los signos o herramientas psicológicas como medios semióticos también encuentran soporte en una concepción antropológica aplicada al proceso educativo. Estamos de acuerdo con Herrero (1992) en señalar que es imposible concebir al ser humano fuera de las relaciones que le ponen en contacto con el otro. 
las condiciones sociales y culturales en las cuales ella acontece.

Consideramos, en particular, que la mediación del lenguaje, además de su importancia en el contacto social, aporta al desarrollo cognitivo varias formas de ser: libertad operacional, independencia del contexto, complejidad de la acción (planeación), autorreflexividad (conciencia del lenguaje, conducta mediata) y control de la conducta (no a los impulsos). En este sentido, estamos de acuerdo con Cárdenas (en prensa) cuando sostiene que desde la perspectiva de Vygotski “[...] la característica básica de la conducta humana en general es que las personas influyen en sus relaciones con el entorno, y a través de dicho entorno modifican su conducta, sometiéndola a su control".

En esta dirección coincidimos en la idea educativa según la cual el desarrollo cultural es un proceso artificial. Como bien lo anota Vygotski (1987, p. 187):

La educación es el desarrollo artificial del niño;

[la educación] es el dominio ingenioso de los procesos naturales del desarrollo y no sólo influye sobre unos u otros procesos del desarrollo, sino que reestructura, de la manera más esencial, todas las funciones de la conducta.

Esta línea cultural de desarrollo vygotskiana requiere, por supuesto, de un complejo y relativamente largo proceso de apropiación cultural. Este proceso estaría orientado a propiciar grados crecientes de dominio autorregulado (consciente y voluntario) y descontextualizado de los instrumentos de mediación semiótica, lo cual posibilitaría en nuestros estudiantes, por ejemplo, formas de conceptualización cada vez más elaboradas o sofisticadas. El principio de descontextualización de los instrumentos de mediación de Vygotski (Wertsch, 1985/1988, pp. 49-50) afirma: "el significado de los signos se vuelve cada vez menos dependiente del contexto espacio-temporal en el que son utilizados"; del que podemos inferir, como lo señala Wertsch (1985/1988, p. 50), que "las formas de calcular observadas en los hombres primitivos eran altamente dependientes del contexto", en otras palabras, el cálculo dependía de la percepción de objetos y entornos concretos.

Se piensa con y a través de los signos, este es uno de los planteamientos que se pueden derivar de la teoría vygotskiana (Vygotski, 1989). Esto sugiere que las maneras como nuestros estudiantes llegan a conocer y lo que conocen llevan en su constitución sedimentos de formas históricas y culturales de pensamiento. En sus actos de conocimiento, los sujetos operan sistemas de significados culturales. Dicha dimensión semiótica los antecede y afecta sus estructuras psíquicas, por ejemplo la precepción y la simbolización.

\section{Referencias}

Bajtín, M. (1929/1992). El marxismo y la filosofía del lenguaje. Madrid: Alianza Editorial.

Bajtín, M. (1979/2009). Estética de la creación verbal. México: Siglo XXI.

Calderón, D. (2005). Dimensión cognitiva y comunicativa de la argumentación en matemáticas [tesis doctoral no publicada]. Universidad del Valle, Cali, Colombia.

Cárdenas, J. A. (en prensa). La mediación en Vygotski. Seminario doctoral Sujeto y Alteridad en el Discurso Pedagógico, Doctorado Interinstitucional en Educación, Bogotá, Colombia.

Cárdenas, J. A. (2009). Literatura, pedagogía y formación en valores. Enunciación, 14, 5-20.

Cárdenas, J. A. \& Ardila, L. F. (2009). Lenguaje, dialogismo y educación. Folios, 29, 37-50.

Castorina, J. A. \& Carretero, M. (Comps.) (2012). Desarrollo cognitivo y educación. Procesos del conocimiento y contenidos específicos (Vol. II). Buenos Aires: Paidós.

Cole, M. (1999). Psicología cultural. Madrid: Morata.

Cole, M. \& Wertsch, J. (1996). Beyond the IndividualSocial Antinomy in Discussions of Piaget and Vygotsky. Human Development 39, 250-256.

D'Amore, B. (2001). Cocepttualizzazione, registri di rappresentazioni semiotiche e noetica. La matemática e la sua didattica, 2, 150-173.

Duval, R. (1999). Semiosis y pensamiento humano: Registros semióticos y aprendizajes intelectuales [Traducción de Miryam Vega]. Cali: Universidad del Valle. 
Universidad Pedagógica Nacional

Facultad de Humanidades

García, J. A. (2006). Identidad y alteridad en Bajtín. Acta Poética, 27(1).

Hegel, G. (1817/2004). Enciclopedia de las ciencias filosóficas. México: Porrúa.

Herrero, C. (Mayo, 1992). Mijail Bajtín y el principio dialógico en la creación literaria y en el discurso humano. Revista Suplementos: Historia de la relación filosofía-literatura, 32 ..

Kozulin, A. (2000). Instrumentos psicológicos: la educación desde una perspectiva cultural. Barcelona: Paidós.

Lamiell, J. T. (2003). Beyond individual and Group Differences. Thousand Oaks, Ca: Sage.

Miranda, I. (2009). Objetivación de saberes científicoculturales relacionados con el movimiento lineal representado con gráficas cartesianas: una experiencia con estudiantes de Bachillerato [tesis doctoral no publicada]. Departamento de Matemática Educativa, Centro de Investigación y de Estudios Avanzados del IPN. México.

Noel, G. (1995). La lógica de Hegel [J. A. Díaz, Trad.]. Bogotá: Editorial Universidad Nacional.

Radford, L. (2013). Three Key Concepts of the Theory of Objectification: Knowledge, Knowing, and Learning. Journal of Research in Mathematics Education, 2(1), 7-44. doi: http://doi.dx.org/10.4471/redimat.2013.19

Sánchez, Y. (2001). Vygotski, Piaget y Freud: A propósito de la socialización. Enunciación, 6, pp. 29-34.

Sánchez, Y. (s.f.). Interacción y desarrollo: El lugar de los estudios sobre las interacciones sociales dentro de la psicología. Diálogos, 4. Discusiones en la psicología contemporánea. Recuperado de internet: http://www. bdigital.unal.edu.co/1299/5/04CAPI03.pdf

Valsiner, J. (2012). "La dialéctica en el estudio del desarrollo”. En Castorina, J. \& Carretero, M. (Comps.), Desarrollo cognitivo y educación. Procesos del conocimiento y contenidos específicos (Vol. II) (pp. 139-162). Buenos Aires: Paidós.

Vygotski, L. (1929). The problem of the cultural development of the child. Journal of Genetic Psychology, $36,415-434$.

Vygotski, L. (1978). Mind in Society: The development of higher psychological processes. Cambridge, MA: Harvard University Press.

Vygotski, L. (1987). Historia del desarrollo de las Funciones Psicológicas Superiores. La Habana: Científico-Técnica.
Vygotski, L. (1988). El desarrollo de los procesos psicológicos superiores [título original: Mind in society: The development of higher psycholgical processes]. México: Grijalbo.

Vygotski, L. (1989). El proceso de formación de la psicología marxista: L. Vygotsky, A. Leontiev, A. Luria. URSS: Progreso.

Vygotski, L. S. (1931/2000). Obras escogidas (Vol. III) (L. Kuper, Trad.). Madrid: Visor.

Vygotski, L. (1934/2007). Pensamiento y habla (A. Ariel González, Trad.). Buenos Aires: Ediciones Colihue.

Wertsch, J. (1988). Vygotsky y la formación social de la mente. Barcelona: Paidós [Versión original: Vygotsky and the social formation of mind, Cambridge: Harvard University Press, 1985].

Wertsch, J. (1991). Voces de la mente. Un enfoque sociocultural para el estudio de la acción mediada. Madrid: Visor.

Wertsch, J. (1998). La mente en acción. Madrid: Aique. 